\title{
Differences in the use of spirometry between rural and urban primary care centers in Spain
}

\author{
This article was published in the following Dove Press journal: \\ International Journal of COPD \\ 17 August 2015 \\ Number of times this article has been viewed
}

\section{Eduardo Márquez-Martín' Joan B Soriano² Myriam Calle Rubio 3 Jose Luis Lopez-Campos ${ }^{1,4}$ \\ On behalf of the $3 \mathrm{E}$ project \\ 'Unidad Médico-Quirúrgica de Enfermedades Respiratorias, Instituto de Biomedicina de Sevilla (IBiS), Hospital Universitario Virgen del Rocío, Universidad de Sevilla, Sevilla, ${ }^{2}$ Instituto de Investigación Hospital Universitario de la Princesa (IISP), Universidad Autónoma de Madrid, Cátedra UAM-Linde, ${ }^{3}$ Servicio de Neumología, Hospital Universitario Clínico San Carlos, ${ }^{4}$ Centro de Investigación Biomédica en Red de Enfermedades Respiratorias (CIBERES), Instituto de Salud Carlos III, Madrid, Spain}

Correspondence: Eduardo MárquezMartín

Hospital Universitario Virgen del Rocío, Avenida Manuel Siurot, s/n, 4I0I3 Sevilla, Spain

Tel +3495 501 3166

Fax +349550I 3166

Email eduardo.marquez.sspa@ juntadeandalucia.es
Objectives: The aim of this study is to evaluate the ability and practice of spirometry, training of technicians, and spirometry features in primary care centers in Spain, evaluating those located in a rural environment against those in urban areas.

Methods: An observational cross-sectional study was conducted in 2012 by a telephone survey in 970 primary health care centers in Spain. The centers were divided into rural or urban depending on the catchment population. The survey contacted technicians in charge of spirometry and consisted of 36 questions related to the test that included the following topics: center resources, training doctors and technicians, using the spirometer, bronchodilator test, and the availability of spirometry and maintenance.

Results: Although the sample size was achieved in both settings, rural centers (RCs) gave a lower response rate than urban centers (UCs). The number of centers without spirometry in rural areas doubled those in the urban areas. Most centers had between one and two spirometers. However, the number of spirometry tests per week was significantly lower in RCs than in UCs (4 [4.1\%] vs $6.9[5.7 \%], P<0.01)$. The availability of a specific schedule for conducting spirometries was higher in RCs than in UCs (209 [73.0\%] vs 207 [64.2\%], $P=0.003)$. RCs were more satisfied with the spirometries ( 7.8 vs $7.6, P=0.019)$ and received more training course for interpreting spirometry ( $41.0 \%$ vs $33.2 \%, P=0.004)$. The performance of the bronchodilator test showed a homogeneous measure in different ways. The spirometer type and the reference values were unknown to the majority of respondents.

Conclusion: This study shows the differences between primary care RCs and UCs in Spain in terms of performing spirometry. The findings in the present study can be used to improve the performance of spirometry in these areas.

Keywords: respiratory functional test, rural health, obstructive lung diseases

\section{Introduction}

Rural and urban communities have distinct characteristics in terms of demographics, social, and physical environments and may vary in access to health care facilities and services. The characteristics of rural patients have been studied in some communities showing sociodemographic differences. ${ }^{1}$ Additionally, important differences have been reported in different respiratory conditions in different countries between rural and urban areas from a epidemiological and clinical standpoint. ${ }^{2,3}$ Of note, disparities in pulmonary function have also been reported. ${ }^{4}$ Examination of geographic variation in disease occurrence and other disease measures provides a method for detection of gaps in quality of public health activities and clinical health care services. ${ }^{5}$

Spirometry is a necessary diagnostic technique for the diagnosis of many prevalent chronic respiratory diseases. In fact, spirometry is the most used guidelines for diagnosis and treatment of chronic obstructive pulmonary disease (COPD) as the Global Initiative for Chronic Obstructive Lung Disease indicates that it is a prerequisite for 
diagnosing the disease and a necessary tool to establish the best treatment possible. ${ }^{6}$ The Global Initiative for Asthma (GINA) recommends spirometry to measure airflow limitation, and its reversibility highlights and confirms the diagnosis of asthma. ${ }^{7}$

In Spain, a recent study was done comparing the use of spirometry in primary and secondary care (3E project). ${ }^{8}$ The study showed important differences in the use, training, and maintenance of spirometers. By using the $3 \mathrm{E}$ database, the aim of the study was to evaluate the ability and practice of spirometry, training of technicians, and spirometry features in primary care centers in Spain, evaluating those located in a rural environment against those in urban areas.

\section{Methods}

This study is a subanalysis of the $3 \mathrm{E}$ project, whose methodology is available elsewhere. ${ }^{8}$ In short, it is a cross-sectional study of 970 primary care centers in Spain that routinely evaluated adult patients with respiratory disease. The questionnaire consisted of 36 items that included the following topics: center resources, training doctors and technicians, using the spirometer, bronchodilator test (BDT), and the availability of spirometry and maintenance. The survey was conducted between January 2012 and March 2012 by telephone, through a semi-structured computer-assisted telephone interview done to the technicians responsible for performing the spirometries with an average of 20 minutes duration.

The aim of this study was to obtain information from $20 \%$ of the primary care centers in Spain. The centers were divided in rural or urban depending on the catchment population ( 25,000 habitants was considered the limit). The present study did not involve human subjects, material, or data, so an ethics committee approval was deemed not to be necessary. All participants gave oral consent to complete the survey.

Data analysis was performed using the Statistical Package for the Social Sciences software version 18.0 (IBM Corporation, Armonk, NY, USA). Description of variables was done using the absolute and relative frequencies for categorical responses. Inferential studies were conducted comparing data from rural centers (RCs) to urban centers (UCs) using chi-square test and Student's $t$-test for independent data. A $P$-value lower than 0.05 was considered statistically significant.

\section{Results}

To survey $20 \%$ of primary care centers in Spain, 970 centers were screened (43.9\% RCs and 56.6\% UCs). Data were obtained from $21.2 \%$ of those in Spain. The response rate was $51.5 \%$ for RCs and $76.4 \%$ for UCs $(P<0.001)$. Of these $266 \mathrm{RCs}$ that were not surveyed, $38.7 \%$ did not have spirometer, $20.7 \%$ did have a spirometer but were not using it, and $40.6 \%$ declined participation. In the 99 UCs that were not surveyed, $46.5 \%$ did not have spirometer, $19.2 \%$ did have a spirometer but were not using it, and $34.3 \%$ refused participation (Figure 1). Accordingly, the number of centers without spirometry in rural areas doubled the urban areas.

In most primary care centers, spirometry was performed only in the center, $264(94.0 \%)$ of RCs and 313 (97.2\%) of UCs. Most centers, both UCs and RCs, had between one and two spirometers (Table 1). However, the number of spirometry tests per week was significantly lower in RCs than in UCs $(P<0.001)$. Among major needs for the performance and interpretation were to have more training $(20.5 \%$ of UCs and $15.9 \%$ of RCs) and adequate room (11.0\% of RCs and $14.6 \%$ of UCs), while major needs for the interpretation of spirometry were being properly trained $(15.8 \%$ of UCs and $17.0 \%$ of RCs), followed by having staff who can interpret them (4.7\% of UCs and $4.2 \%$ of RCs). The availability of a specific schedule for conducting spirometries in absolute numbers is very close but in percentage was higher in $\mathrm{RCs}$ than in UCs $(P=0.003)$.

Staff and training outcomes are summarized in Table 2. Nurses were the main professional who did spirometries both in RCs and UCs, but mostly in UCs $(P=0.005)$. Most centers had received some training for performing spirometry. In most centers, this training was both theoretical and practical, but usually at only one point with a mean of 22.5 months from the last training in RCs and 18.5 months in UCs, without training further repeated. RCs were more satisfied with the spirometries ( $7.8 \mathrm{vs}$ 7.6, $P=0.019)$ and passed more training course for interpreting spirometry ( $41.0 \%$ vs $33.2 \%, P=0.004)$.

Regarding using the spirometer (Table 3), the majority of the indications were to the study of asthma or COPD, with an estimated number of spirometry considered invalid approximately $10 \%$.

The realization of the BDT (Table 4) was performed homogeneously, which is demonstrated by analyzing different points. According to current recommendations, ${ }^{9}$ an improvement in either forced vital capacity (FVC) or forced expiratory volume in 1 second $\left(\mathrm{FEV}_{1}\right)$ was considered reversible. Most centers used short-acting $\beta_{2}$ agonists for BDT, but in general, the number of inhalations was often insufficient and time to wait was often incorrect. The criteria for considering a positive BDT were right in almost half of the respondents. 


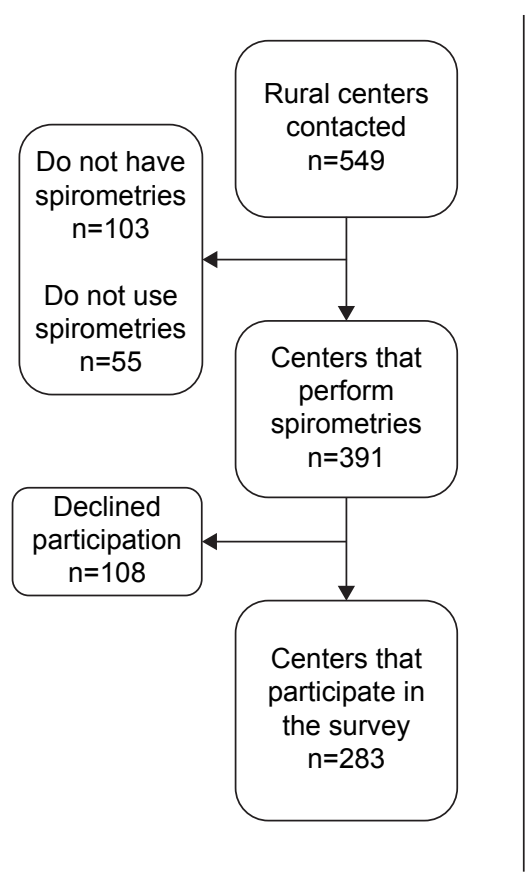

Figure I Flowchart of the centers surveyed.

The spirometer type and the reference values were unknown to the majority of responding technicians (Table 5); UCs used values of the Spanish Society and RCs had a greater ignorance of the values used.

Finally, information on the maintenance of the spirometer is summarized in Table 6 . Not all centers calibrated the spirometer daily. When asked for the reason of not calibrating, the most common response was nonavailability of syringe calibration or nonrequirement by the device.

\section{Discussion}

The study of 3E project highlights the differences between primary care UCs and RCs in Spain in terms of scope of practice of spirometry. The principal findings are differences in the number of spirometry performed and specific

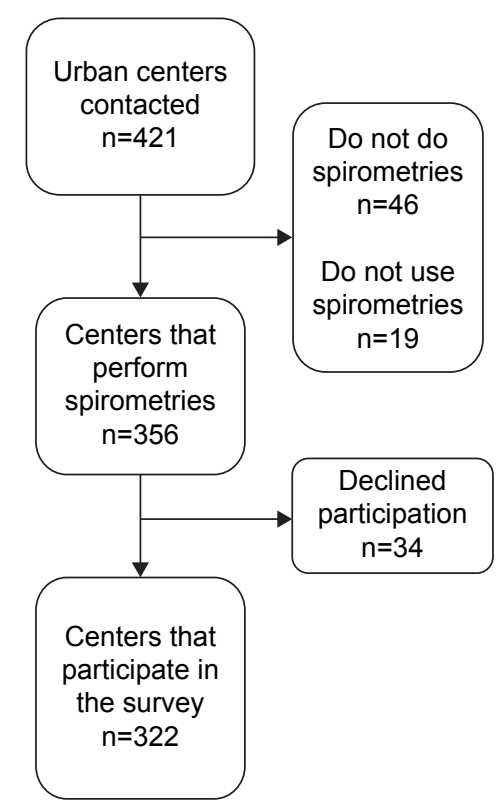

planning, which is higher in UCs than in RCs; satisfaction with the performance of spirometry and the number of centers receiving courses for interpretation, which is higher in $\mathrm{RCs}$ than UCs; and the use and knowledge of the reference values, which is higher in UCs than in RCs.

This is the first survey that was published in Spain with national coverage, whose results were partially published previously. ${ }^{10,11}$ The most important strength of our study is the analysis of the rural and urban population in terms of performing spirometry, something that had not been described previously. The main contribution of this study is the large sample size, with a representation of the entire national territory and a protocol applied evenly. However, there are a number of limitations that should be considered. The first one is that the survey was conducted to the technician who did the test.

Table I Information on center resources

\begin{tabular}{|c|c|c|c|}
\hline & Urban $(n=322)$ & Rural (n=283) & P-value* \\
\hline Number of spirometers per center & I.I7 (0.4) & I.II (0.3) & 0.080 \\
\hline Spirometry done only in that center (\%) & $313(97.2)$ & $264(94.0)$ & 0.022 \\
\hline Spirometry done in different centers with portable spirometer (\%) & $3(0.9)$ & $8(1.3)$ & 0.08 \\
\hline Spirometry done in different centers with the spirometer of the center (\%) & $6(1.9)$ & $9(3.2)$ & 0.29 \\
\hline Average number of spirometries conducted per week & $6.9(5.7)$ & $4.0(4.1)$ & $<0.001$ \\
\hline Centers with no perceived needs regarding the performance of spirometry (\%) & $122(37.9)$ & $127(44.9)$ & 0.083 \\
\hline Centers with no perceived needs regarding interpretation (\%) & $218(67.7)$ & $203(71.7)$ & 0.289 \\
\hline Centers with specific time and schedule (\%) & $207(64.2)$ & $209(73.9)$ & 0.003 \\
\hline Centers with allocated room (\%) & $219(68.2)$ & $176(62.2)$ & 0.124 \\
\hline
\end{tabular}

Notes: *P-values between rural and urban centers are calculated by unpaired Student's $t$-test or $\chi^{2}$ test as appropriate. Data are expressed as mean (standard deviation) or absolute (relative) frequencies (\%). Bold numbers mean significant statistical differences. 
Table 2 Information regarding staff and training

\begin{tabular}{|c|c|c|c|}
\hline & Urban $(n=322)$ & Rural ( $n=283)$ & P-value* \\
\hline Centers with spirometries done by a nurse (\%) & $320(99.4)$ & $27 \mid(95.8)$ & 0.005 \\
\hline Centers that received any training course for conducting spirometry (\%) & $268(83.2)$ & $243(85.9)$ & 0.431 \\
\hline \multicolumn{4}{|l|}{ Type of spirometry training course received } \\
\hline Theoretical and practical & $207(64.3)$ & $201(7 I .0)$ & 0.204 \\
\hline Only theoretical & $44(13.7)$ & $30(10.6)$ & 0.286 \\
\hline Only practical & $57(17.7)$ & $38(13.4)$ & 0.176 \\
\hline Level of satisfaction with your own training $(1-10)^{\dagger}$ & $7.04(1.6)$ & $7.06(1.7)$ & 0.845 \\
\hline Centers' interpretation done by a general practitioner (\%) & $316(98.1)$ & $272(96.1)$ & 0.146 \\
\hline Level of satisfaction with spirometries $(1-10)^{\dagger}$ & $7.6(1.3)$ & $7.8(1.1)$ & 0.019 \\
\hline Centers that received any training course for interpretation (\%) & $107(33.2)$ & $116(41.0)$ & 0.004 \\
\hline
\end{tabular}

Notes: $* P$-values between rural and urban centers are calculated by unpaired Student's $t$-test or $\chi^{2}$ test as appropriate. Data are expressed as mean (standard deviation) or absolute (relative) frequencies (\%). 'Level of satisfaction was evaluated using a scale from I (lowest satisfaction) to I0 (highest satisfaction). Bold numbers mean significant statistical differences.

Table 3 Information regarding spirometer use

\begin{tabular}{|c|c|c|c|}
\hline & Urban $(n=322)$ & Rural (n=283) & $P$-value \\
\hline $\begin{array}{l}\text { Estimation of percentage of spirometries not valid (\%) as judged by the technician } \\
\text { surveyed }\end{array}$ & $9.7(10.8)$ & $9.8(10.6)$ & 0.994 \\
\hline Any previous information given to the patient (\%) & $282(87.6)$ & $246(86.9)$ & 0.886 \\
\hline \multicolumn{4}{|l|}{ Main indications } \\
\hline Asthma (\%) & $33.9(19.5)$ & $31.7(19.6)$ & 0.201 \\
\hline COPD (\%) & $47.8(20.4)$ & $51.6(23.7)$ & 0.046 \\
\hline Other respiratory diseases $(\%)$ & $10.6(14.4)$ & $9.4(14.7)$ & 0.314 \\
\hline
\end{tabular}

Notes: $* P$-values between rural and urban centers are calculated by unpaired Student's $t$-test or $\chi^{2}$ test as appropriate. Data are expressed as absolute (relative) frequencies (\%). Bold numbers mean significant statistical differences.

Abbreviation: COPD, chronic obstructive pulmonary disease.

Table 4 Information regarding the bronchodilator test

\begin{tabular}{|c|c|c|c|}
\hline & Urban $(n=322)$ & Rural $(n=283)$ & $\boldsymbol{P}$-value* \\
\hline \multicolumn{4}{|l|}{ Indication to suspend inhalers before spirometry } \\
\hline Always (\%) & $297(92.2)$ & $260(91.9)$ & 0.881 \\
\hline Occasionally (\%) & $12(3.7)$ & $8(2.8)$ & 0.651 \\
\hline Never (\%) & $13(4.0)$ & $15(5.3)$ & 0.562 \\
\hline Percentage of patients' test not done for not having withdrawn inhalers (\%) & $6.6(12.9)$ & $4.9(7.9)$ & 0.053 \\
\hline \multicolumn{4}{|l|}{ Which drugs do you have available for the bronchodilator test } \\
\hline Salbutamol (\%) & $299(92.9)$ & $270(95.4)$ & 0.228 \\
\hline Terbutaline (\%) & $24(7.5)$ & $31(I I .0)$ & 0.157 \\
\hline Ipratropium (\%) & $12(3.7)$ & $22(7.8)$ & 0.034 \\
\hline \multicolumn{4}{|l|}{ Which one of them do you normally use? } \\
\hline Salbutamol (\%) & $296(94.3)$ & $265(96.4)$ & 0.251 \\
\hline Terbutaline (\%) & $15(4.8)$ & $7(2.5)$ & 0.193 \\
\hline Ipratropium (\%) & $3(1.0)$ & $3(1.1)$ & 1.000 \\
\hline \multicolumn{4}{|l|}{ How many inhalations you give? } \\
\hline Salbutamol & $2.6(0.8)$ & $2.6(0.8)$ & 0.784 \\
\hline Terbutaline & $2.3(0.6)$ & $2.1(0.6)$ & 0.200 \\
\hline Ipratropium & $2.3(0.7)$ & $2.1(0.4)$ & 0.209 \\
\hline \multicolumn{4}{|l|}{ How long do you wait for the second spirometry? } \\
\hline $10 \min (\%)$ & $59(19)$ & $50(\mid 8.3)$ & 0.915 \\
\hline $15 \min (\%)$ & $149(47.9)$ & 117 (42.9) & 0.244 \\
\hline $20 \min (\%)$ & $84(27.0)$ & $86(31.5)$ & 0.237 \\
\hline $30 \min (\%)$ & $12(3.9)$ & II (4.0) & 1.000 \\
\hline Criterion to consider a positive bronchodilator test is increasing I $2 \%$ and $200 \mathrm{~mL}(\%)$ & $117(58.5)$ & $74(52.1)$ & 0.270 \\
\hline
\end{tabular}

Notes: $* P$-values between rural and urban centers are calculated by unpaired Student's $t$-test or $\chi^{2}$ test as appropriate. Data are expressed as mean (standard deviation) or absolute (relative) frequencies (\%). Bold numbers mean significant statistical differences.

Abbreviation: min, minutes. 
Table 5 Information regarding spirometer features

\begin{tabular}{|c|c|c|c|}
\hline & $\begin{array}{l}\text { Urban } \\
(n=322)\end{array}$ & $\begin{array}{l}\text { Rural } \\
(n=283)\end{array}$ & $P$-value* \\
\hline \multicolumn{4}{|l|}{ Type of transducer } \\
\hline Pneumotachometer (\%) & $52(16.1)$ & $39(13.8)$ & 0.428 \\
\hline Turbine (\%) & $119(37.0)$ & $106(37.5)$ & 0.933 \\
\hline Curves only on the screen (\%) & $299(92.9)$ & $258(91.2)$ & 0.455 \\
\hline \multicolumn{4}{|l|}{ Reference values } \\
\hline SEPAR (\%) & $124(38.5)$ & $83(29.3)$ & 0.020 \\
\hline ERS (\%) & $5(1.6)$ & I $(0.4)$ & 0.222 \\
\hline Do not know/answer (\%) & $190(59.0)$ & $196(69.3)$ & 0.011 \\
\hline
\end{tabular}

Notes: $* P$-values between rural and urban centers are calculated by unpaired Student's t-test or $\chi^{2}$ test as appropriate. Data are expressed as absolute (relative) frequencies (\%). Bold numbers mean significant statistical differences.

Abbreviations: SEPAR, Sociedad Española de Neumología y Cirugía Torácica; ERS, European Respiratory Society.

This way of performing the survey are beneficial in that the questions are to the person that daily performed the test, although when assessing questions about the interpretation of results have to be cautious. Additionally, the work has been done through a telephone survey, which has the advantages of access to centers with less resource, be faster than the mail or personal interviews, and to survey a large number of centers but always carries some degree of non-response and make necessary to confirm the veracity of what the respondent answered. Survey was self-reported, in which remained external validity. But because the response rate was high, we trusted the validity and representativeness of the data obtained. Finally, in order to encourage participation, we deliberately limited the number of questions to those which we thought were most relevant. It is then possible that some relevant aspects of spirometry may have been left out. In particular, the quality criteria to consider a valid spirometry were not included in the survey. In addition, one interesting approach for the future would be to correlate our findings with the clinical management of the patients in order to evaluate if performing a correct spirometry may have some influence on clinical care provided to patients or on clinical outcomes.

Spirometry is an essential technique for the diagnosis of prevalent diseases such as asthma or COPD. However, its use in primary care centers is not widely achieved. In Spain, only half of the patients diagnosed with COPD in primary care had a spirometry, ${ }^{12}$ which has also been identified in other countries like the USA in studies with more than 90,000 patients. $^{13}$ People with unrecognized COPD may miss the opportunity to improve their health status because of lack of performance of functional tests. ${ }^{14}$ The evaluation of the variability among rural and urban regions is essential in order to explore the situation in Spain. This variability in primary care has also been described within other countries. In Italy, a study conducted on 617,280 patients revealed that treatment was usually prescribed without performing pulmonary function tests or without taking into account the severity of airway obstruction. ${ }^{15}$ Importantly, COPD patients in rural areas have been associated with worse health status and greater impairment. ${ }^{16}$ There is little information in Spain to analyze the characteristics of the population using these services. In order to make informed decisions about the allocation of resources, it seems important to know more information on these patients than the number of patients who have undergone spirometry.

One of the most important points of our study is the finding of the low number of spirometry tests that are done in the primary care centers in Spain. Differences between UCs and RCs are shown both in spirometry number and programming the time and schedule. Rural and urban communities

Table 6 Information regarding spirometer maintenance

\begin{tabular}{|c|c|c|c|}
\hline & Urban $(n=322)$ & Rural (n=283) & $P$-value \\
\hline \multicolumn{4}{|l|}{ Meteorological information } \\
\hline Automatically provided by the device (\%) & $153(50.3)$ & I2I (45.7) & 0.275 \\
\hline Meteorological station in the room (\%) & $97(31.9)$ & $94(35.5)$ & 0.375 \\
\hline \multicolumn{4}{|l|}{ How often do you calibrate the spirometer? } \\
\hline Every day it is used (\%) & $119(37.0)$ & II5 (40.6) & 0.551 \\
\hline Never $(\%)$ & $32(9.9)$ & $26(9.2)$ & 0.909 \\
\hline \multicolumn{4}{|l|}{ Reasons for not never calibrating } \\
\hline Do not have the calibrating syringe (\%) & $8(25.0)$ & $10(38.0)$ & 0.393 \\
\hline The device does not require it (\%) & $8(25.0)$ & $6(23.1)$ & 0.946 \\
\hline There is a person in charge of the maintenance (\%) & $186(57.8)$ & $179(63.3)$ & $0.28 \mathrm{I}$ \\
\hline \multicolumn{4}{|l|}{ How often do you do maintenance? } \\
\hline More than once a day (\%) & $56(17.4)$ & $59(20.8)$ & 0.469 \\
\hline Once a month (\%) & $60(18.6)$ & $59(20.8)$ & 0.631 \\
\hline Use a different filter for every patient (\%) & $257(79.8)$ & $229(80.9)$ & 0.909 \\
\hline
\end{tabular}

Notes: *P-values between rural and urban centers are calculated by unpaired Student's $t$-test or $\chi^{2}$ test as appropriate. Data are expressed as absolute (relative) frequencies (\%). 
have distinct characteristics in terms of demographic, social, and physical environments and may vary in access to health care facilities and services. Some studies have shown that in certain areas such as in Canada, rural residents tend to be older and are more likely to be obese, have less education, and have lower income than urban residents. ${ }^{17}$ Rural populations also have a higher prevalence of chronic conditions such as diabetes and heart disease. ${ }^{18}$ End-oflife decisions in COPD are also different in rural areas in Spain. ${ }^{19}$ However, rural residents report several barriers to accessing health care, including transportation difficulties and distance to care, social isolation, financial constraints, limited health care facilities (hospitals and pharmacies), physician shortages, and lack of access to specialist care. The lack of access to primary care physicians, specialists, or health care facilities could result in decreased prescribing of evidence-based medications. In fact, in a sample of COPD patients in the USA, it was found that rural residents were associated with poorer health status and higher levels of utilization of selected health care services compared to urban residents. ${ }^{16}$ Because rural communities have a higher proportion of older residents, there is a higher demand of health care services for chronic conditions; hence, the services provided should be better.

Another important finding in this study is the difference found in the degree of satisfaction with spirometry and the number of centers that perform training courses for interpretation of spirometry. Training is surprisingly higher in RCs than in UCs. Spirometry is not an extremely difficult technique to perform but requires learning, and this is maintained over time. This is what the European Respiratory Society aimed with the dissemination of a spirometry training program within Europe. ${ }^{20}$ Educational program had a very limited impact on general practitioners' clinical practice. The usage of spirometry is poor with the general practitioners tending to perform more chest X-rays than pulmonary function tests. ${ }^{21}$ In our study, it appears that the satisfaction and the amount of training is higher in RCs than in UCs.

The usefulness of the BDT in the diagnosis and treatment of asthma and COPD has been and continues to be a source of debate. Despite its simplicity, it remains difficult to interpret and translate into specific therapeutic strategies, particularly in COPD. ${ }^{22}$ In our study, it seems that there are few differences between the UCs and RCs. As for the bronchodilator used, we enquired on the most commonly used. However, it is possible that some centers used more than one, but the survey did not ask for this possibility and the respondents were forced to choose one.
Calibration is absolutely necessary, this being one of the weaknesses we have observed with our work. In our study, we found no differences in calibration, but it stresses that not all centers' spirometers calibrated daily. We believe that these data should be assessed and encourage health authorities to take the necessary measures to resolve this problem that can cause problems in diagnosis.

In summary, this study shows the differences between primary care RCs and UCs in Spain in terms of performing spirometry. In RCs, less spirometries are performed, but the degree of satisfaction and the number of training sessions are greater in UCs. These findings can be used to improve and standardize health care resources to ensure similar coverage to the entire population, regardless of the area in which resides.

\section{Acknowledgments}

This study was conducted on behalf of the $3 \mathrm{E}$ project of which the following people were involved: Steering committee; Myriam Calle Rubio, Joan B Soriano, Jose Luis Lopez-Campos. Working panel (by alphabetical order of the scientific society they represent); AIRE, Borja Garcia Cosio, Isabel Mir. ASTURPAR, Cristina Martínez González. NEUMOCAN, Ana Velázquez. NEUMOMADRID, Jose Miguel Rodríguez González-Moro. NEUMOSUR, Aurelio Arnedillo. SADAR, Luis Borderias Clau. SEAR, Juan Antonio Riesco Miranda. SEPAR, Juan Ruiz Manzano (president), German Peces Barba. SOCALPAR, Jose Luis Viejo Bañuelos. SOCAMPAR, Encarnación López Gabaldón (president). SOCAP, Eduard Monso Molas (president). SOGAPAR, Marina Blanco Aparicio. SOMUPAR, Juan Luis de la Torre Alvaro (president). SVNEUMO, Mª Cruz González Villaescusa. SVNPR, Juan Bautista Galdiz.

\section{Disclosure}

The authors report no conflicts of interest in this work.

\section{References}

1. Smith KB, Humphreys JS, Wilson MG. Addressing the health disadvantage of rural populations: how does epidemiological evidence inform rural health policies and research? Aust J Rural Health. 2008;16(2): 56-66.

2. Wang S, Kou C, Liu Y, et al. Rural-urban differences in the prevalence of chronic disease in northeast China. Asia Pac J Public Health. 2015; 27(4):394-406.

3. O'Leary ST, Barnard J, Lockhart S, et al. Urban and rural differences in parental attitudes about influenza vaccination and vaccine delivery models. J Rural Health. 2015. Accessed May 7, 2015. doi: 10.1111/ jrh.12119. Epub ahead of print.

4. Sonnappa S, Lum S, Kirkby J, et al. Disparities in pulmonary function in healthy children across the Indian urban-rural continuum. Am J Respir Crit Care Med. 2015;191(1):79-86. 
5. Radley DC, Schoen C. Geographic variation in access to care - the relationship with quality. $N$ Engl J Med. 2012;367(1):3-6.

6. Global Initiative for Obstructive Lung Disease. Available from: www.goldcopd.org. Accessed May 20, 2015

7. Boulet LP, FitzGerald JM, Levy ML, et al. A guide to the translation of the Global Initiative for Asthma (GINA) strategy into improved care. Eur Respir J. 2012;39(5):1220-1229.

8. López-Campos JL, Soriano JB, Calle M; Encuesta de Espirometría en España (3E) Project. A comprehensive, national survey of spirometry in Spain: current bottlenecks and future directions in primary and secondary care. Chest. 2013;144(2):601-609.

9. Pellegrino R, Viegi G, Brusasco V, et al. Interpretative strategies for lung function tests. Eur Respir J. 2005;26(5):948-968.

10. Lopez-Campos JL, Soriano JB, Calle M; 3E Project. Determinants of use of the bronchodilator test in primary and secondary care: results of a national survey in Spain. Clin Respir J. 2014. Epub ahead of print.

11. López-Campos JL, Soriano JB, Calle M; 3E Project. Inter-regional changes in the performance and interpretation of spirometry in Spain: 3E study. Arch Bronconeumol. 2014;50(11):475-483.

12. Monteagudo M, Rodriguez-Blanco T, Parcet J, et al. Variability in the performing of spirometry and its consequences in the treatment of COPD in primary care. Arch Bronconeumol. 2011;47(5):226-233.

13. Joo MJ, Lee TA, Weiss KB. Geographic variation of spirometry use in newly diagnosed COPD. Chest. 2008;134(1):38-45.

14. Yawn BP, Wollan PC. Knowledge and attitudes of family physicians coming to COPD continuing medical education. Int J Chron Obstruct Pulmon Dis. 2008;3(2):311-317.
15. Cazzola M, Bettoncelli G, Sessa E, Cricelli C. Primary care of the patient with chronic obstructive pulmonary disease in Italy. Respir Med. 2009;103(4):582-588.

16. Jackson BE, Coultas DB, Suzuki S, Singh KP, Bae S. Rural-urban disparities in quality of life among patients with COPD. J Rural Health. 2013;29(suppl 1):s62-s69.

17. Vanasse A, Courteau J, Cohen AA, Orzanco MG, Drouin C. Rural-urban disparities in the management and health issues of chronic diseases in Quebec (Canada) in the early 2000s. Rural Remote Health. 2010; 10(4):1548.

18. Banegas JR, Rodriguez-Artalejo F, de la Cruz Troca JJ, et al. Blood pressure in Spain: distribution, awareness, control, and benefits of a reduction in average pressure. Hypertension. 1998;32(6):998-1002.

19. López-Campos JL, Ruiz-Ramos M, Mendez C, García-León J. Characteristics of subjects who died of chronic obstructive pulmonary disease in Andalusia in 2010 and 2011. J Palliat Med. 2013;16(12):1610-1613.

20. Steenbruggen I, Mitchell S, Severin T, et al. Harmonising spirometry education with HERMES: training a new generation of qualified spirometry practitioners across Europe. Eur Respir J. 2011;37(3):479-481.

21. Bertella E, Zadra A, Vitacca M. COPD management in primary care: is an educational plan for GPs useful? Multidiscip Respir Med. 2013; $8(1): 24$.

22. Calverley PM, Albert P, Walker PP. Bronchodilator reversibility in chronic obstructive pulmonary disease: use and limitations. Lancet Respir Med. 2013;1(7):564-573.
International Journal of COPD

\section{Publish your work in this journal}

The International Journal of COPD is an international, peer-reviewed journal of therapeutics and pharmacology focusing on concise rapid reporting of clinical studies and reviews in COPD. Special focus is given to the pathophysiological processes underlying the disease, intervention programs, patient focused education, and self management protocols.

\section{Dovepress}

This journal is indexed on PubMed Central, MedLine and CAS. The manuscript management system is completely online and includes a very quick and fair peer-review system, which is all easy to use. Visit http://www.dovepress.com/testimonials.php to read real quotes from published authors. 